\title{
Sex hormone modulation of serotonin-induced coronary vasodilation in isolated heart
}

\author{
M.R. Moysés ${ }^{1}$, \\ L.A. Barker ${ }^{2}$ \\ and A.M. Cabral ${ }^{1}$
}

\author{
'Departamento de Ciências Fisiológicas, Centro Biomédico, \\ Universidade Federal do Espírito Santo, Vitória, ES, Brasil \\ ${ }^{2}$ Department of Pharmacology and Experimental Therapeutics, \\ Louisiana State University, Health Sciences Center, N ew O rleans, LA, USA
}

\author{
Correspondence \\ M.R. Moysés \\ Programa de Pós-Graduação \\ Departamento Ciências Fisiológicas \\ CBM, UFES \\ Av. Marechal Campos, 1468 \\ 29050-090 Vitória, ES \\ Brasil \\ Fax: + 55-27-335-7330 \\ E-mail: mrmoyses@npd.ufes.br
}

Received July 31, 2000

Accepted March 27, 2001

\section{Abstract}

The present study was designed to evaluate the differences in the coronary vasodilator actions of serotonin $(5-\mathrm{HT})$ in isolated heart obtained from naive or castrated male and female rats that were treated with either estrogen or testosterone. Hearts from 12 groups of rats were used: male and female naive animals, castrated, castrated and treated with $17 ß$-estradiol $\left(0.5 \mu \mathrm{g} \mathrm{kg}^{-1} \mathrm{day}^{-1}\right)$ for 7 or 30 days, and castrated and treated with testosterone $\left(0.5 \mathrm{mg} \mathrm{kg}^{-1}\right.$ day $\left.^{-1}\right)$ for 7 or 30 days. After treatment, the vascular reactivity of the coronary bed was evaluated. Baseline coronary perfusion pressure (CPP) was determined and dose-response curves to 5-HT were generated. Baseline CPP differed between male $(70 \pm 6 \mathrm{mmHg}, \mathrm{N}=10)$ and female (115 $\pm 6 \mathrm{mmHg}, \mathrm{N}=12$ ) naive rats. Maximal 5-HT-induced coronary vasodilation was higher $(\mathrm{P}<0.05)$ in naive female than in naive male rats. In both sexes, 5-HT produced endothelium-dependent coronary vasodilation. After castration, there was no significant difference in baseline CPP between hearts obtained from male and female rats (75 $\pm 7 \mathrm{mmHg}, \mathrm{N}=8$, and $83 \pm 5 \mathrm{mmHg}, \mathrm{N}=8$, respectively). Castration reduced the 5 -HT-induced maximal vasodilation in female and male rats $(\mathrm{P}<0.05)$. Estrogen treatment of castrated female rats restored $(\mathrm{P}<0.05)$ the vascular reactivity. In castrated male rats, 30 days of estrogen treatment increased $(\mathrm{P}<0.05)$ the responsiveness to 5 -HT. The endothelium-dependent coronary vasodilator actions of 5-HT are greater in female rats and are modulated by estrogen. A knowledge of the mechanism of action of estrogen on coronary arteries could aid in the development of new therapeutic strategies and potentially decrease the incidence of cardiovascular disease in both sexes.

\section{Introduction}

Coronary artery disease is an important cause of morbidity and mortality. The disease involves increased vasoconstrictor responses, enhanced interaction of circulating blood cells with blood vessel walls and proliferation and migration of vascular smooth
Key words

- Coronary circulation

- Endothelial function

- Estradiol

- Smooth muscle
- Serotonin 
is known about the mechanisms underlying this phenomenon, epidemiological and experimental evidence indicates that female sex hormones, in particular 17ß-estradiol, have protective effects against cardiovascular diseases $(5,6)$ because estrogen replacement therapy reduces the incidence of coronary artery disease $(7,8)$.

A number of potential mechanisms for the protective effect of estrogens on coronary arteries have been proposed. Estrogen has a beneficial effect on plasma lipoproteins, increasing HDL cholesterol and decreasing LDL cholesterol (9). Although early studies suggested that 50 to $60 \%$ of the protective effect of estrogens on coronary disease was due to the favorable changes in plasma lipids, recent data suggest that this protection is closer to $25 \%(10,11)$. Estrogen also appears to inhibit cholesterol deposition on arterial walls (12). Moreover, estrogen has a number of other properties that may result in cardiovascular protection. For instance, a considerable body of data suggest that an important protective effect of estrogen is to potentiate the actions of endothelium-derived relaxing factors (13-15). Additionally, estrogen can enhance the effects of calcium channel blocking agents (16). Studies of the acute hemodynamic effects of estrogen have reported increases in cardiac output and peripheral blood flow in both humans and experimental animals (17). 17ßEstradiol has been shown to induce relaxation of precontracted coronary artery rings and to inhibit calcium influx in isolated cardiac myocytes (18). Only a few studies have addressed the actions of estrogen on the coronary vascular bed. Although there are clear indications that endothelial function is altered by estrogens, the effects of endogenous estrogens on the coronary vascular actions of serotonin (5-HT) have not yet been elucidated for the entire coronary bed. The effects of 5-HT, an autacoid released during platelet aggregation, have been evaluated in some preparations of coronary arteries in vitro and in vivo. 5-HT is a potent vasodilator of the coronary bed in isolated hearts and in situ $(19,20)$ and may have an important role in coronary tone in patients with healthy coronary arteries. 5-HT causes a dose-dependent increase in coronary blood flow, as well as an increase in coronary artery diameter that is mediated by endothelial relaxing factors (21). In contrast, in patients with coronary atherosclerotic lesions or impaired endothelium, 5-HT causes a dose-dependent vasoconstriction (20).

The present study was designed to evaluate the differences in vascular reactivity to 5 HT between males and females and to evaluate the effects of castration and treatment with sex hormones on the modulation of the vascular reactivity of the coronary vascular bed to 5 -HT in isolated hearts.

\section{Material and Methods}

The investigation was conducted in compliance with the Guide for Biomedical Research, as stated by the Brazilian Societies of Experimental Biology, and with the guiding principles of other physiological societies for research involving animals. The experiments were performed on isolated perfused hearts from young ( 3 months old) male and female Wistar rats. Under ether anesthesia, half of the male and female rats used were castrated and left untreated for 30 days. Twelve groups of male and female animals were used in the present study: naive, castrated, castrated and treated with 17ß-estradiol propionate $\left(0.5 \mu \mathrm{g} \mathrm{kg}^{-1}\right.$ day $^{-1}$; Sigma Chemical Co., St. Louis, MO, USA) for 7 or 30 days, and castrated and treated with testosterone enanthate $\left(0.5 \mathrm{mg} \mathrm{kg}^{-1}\right.$ day $^{-1}$; Sigma $)$ for 7 or 30 days. The estrous cycle of naive female rats was continuously monitored through vaginal smears. This group was submitted to the experimental protocol one day after the day of estrus. The treated animals received daily $s c$ injections of $17 ß$-estradiol or testosterone dissolved in sunflower seed oil. 
After the different treatment periods the rats were anesthetized with pentobarbital sodium $(40 \mathrm{mg} / \mathrm{kg}$, ip $)$ and injected $s c$ with heparin (100 units/kg). Fifteen minutes after heparin injection, the rats were killed and the hearts were excised immediately and perfused at a constant flow. The studies on the responsiveness of the coronary vascular bed were performed on whole hearts using a Langendorff preparation for perfused isolated hearts. Briefly, using a Langendorff apparatus (Hugo Sachs Electronics, MarchHugstetten, Germany), the isolated hearts were perfused with modified Krebs solution containing $120 \mathrm{mM} \mathrm{NaCl}, 1.26 \mathrm{mM} \mathrm{CaCl}_{2} \cdot 2$ $\mathrm{H}_{2} \mathrm{O}, 5.4 \mathrm{mM} \mathrm{KCl}, 2.5 \mathrm{mM} \mathrm{MgSO}_{4} \cdot 7 \mathrm{H}_{2} \mathrm{O}$,

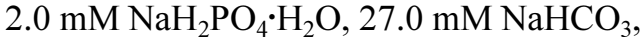
$1.2 \mathrm{mM} \mathrm{Na}_{2} \mathrm{SO}_{4}, 0.03 \mathrm{mM}$ EDTA, and 11.0 $\mathrm{mM}$ glucose, equilibrated with $95 \%$ oxygen and $5 \%$ carbon dioxide at a controlled pressure of $100 \mathrm{mmHg}$ to give a $\mathrm{pH}$ of 7.4, perfused at a rate of $10 \mathrm{ml} / \mathrm{min}$ with a peristaltic pump (MS-Reglo 4 channels, Hugo Sachs Electronics), and kept at $36^{\circ} \mathrm{C}$. A fluidfilled balloon was introduced into the left ventricle through a steel cannula with a latex balloon and connected to a P23Db Statham Pressure Transducer for measuring the isovolumetric cardiac force. The balloon was pressurized by a spindle syringe until it reached a preload of $10 \mathrm{mmHg}$.

Coronary perfusion pressure (CPP) was monitored with a P23Db Statham Transducer connected to a sidearm of the aortic perfusion catheter. Once the preparation was stabilized, baseline CPP was measured after about one hour and dose-response curves to 5-HT (5-hydroxytryptamine creatine sulfate; Sigma) were constructed by single injections administered at 10-min intervals. 5-HT $(0.01$ to $400 \mu \mathrm{g})$ was administered as a bolus injection in a volume of $0.1 \mathrm{ml}$ saline. In the naive male and female groups, dose-response curves for 5-HT were constructed before and after endothelium denudation by infusion of sodium deoxycholate (deoxycholic acid, $2 \mathrm{mg} / \mathrm{ml}$, for $10 \mathrm{~min}$ ).
In all treatment groups, immediately prior to removing the hearts, blood samples were collected via puncture of the abdominal aorta to measure circulating levels of sex hormones. The blood samples were centrifuged immediately at $3000 \mathrm{rpm}$ at $4^{\circ} \mathrm{C}$ for $10 \mathrm{~min}$ to obtain plasma, which was kept at $-20^{\circ} \mathrm{C}$ for later measurement of testosterone and estradiol concentration by radioimmunoassay (Diagnostic Products Corporation, Los Angeles, CA, USA).

At the end of each experiment the left and right ventricles were removed and wet weights were measured. In some experiments using naive male and female animals, after the completion of dose-response curves to 5HT, the coronary vascular bed was perfused with $10 \%$ neutral buffered formalin at a flow rate of $8 \mathrm{ml} / \mathrm{min}$ for $1 \mathrm{~h}$. After weighing, both ventricles were immersed in $10 \%$ neutral formalin. Serial tissue blocks were cut at approximately $3-\mathrm{mm}$ intervals and perpendicular to the long axis of the heart. Histological sections were stained with hematoxylin/eosin.

\section{Statistical analysis}

Dose-response data were analyzed by nonlinear regression analysis for fit to the equation: $\mathrm{E}=\mathrm{E}_{\max } /\left(1+\left(10^{\mathrm{X}} / 10^{\mathrm{B}}\right)^{\mathrm{n}}\right)$, where $\mathrm{E}$ is the observed response, $E_{\max }$ is the maximum response, $\mathrm{X}$ is the logarithm of the dose of 5-HT, B is the logarithm of the dose of 5HT producing one-half maximal response $\left(\log \mathrm{ED}_{50}\right)$, and $\mathrm{n}$ is a curve fitting parameter that defines the slope of the dose-responses curve. The Prism 2 software (GraphPad Software, San Diego, CA, USA) was used.

The data are reported as means \pm SEM. The InStat software (GraphPad Software) was used for statistical analysis. Where appropriate, one-way analysis of variance followed by the Dunnett post hoc test for comparison of treatment groups to their respective controls was performed to determine if the different treatments had effects on sero- 
tonin-induced coronary vasodilation. The correlation between baseline CPP levels and ventricle weight was assessed by the Pearson partial correlation coefficient adjusted for the rat weight. We used the partial coefficient of determination to measure the marginal effects of baseline CPP levels and ventricle weight. The level of significance was set at $5 \%$.

\section{Results}

\section{Baseline coronary perfusion pressure}

The data for baseline CPP in each treatment group are summarized in Table 1. Baseline CPP was significantly higher in female than in male naive rats. Castration had no effect on baseline CPP in hearts obtained from male rats. In female rats, castration caused a significant reduction $(\mathrm{P}<0.01)$ in baseline CPP relative to naive control female rats.

In castrated female rats, the baseline $\mathrm{CPP}$ in hearts obtained after 7 or 30 days of estrogen was not significantly different from that of the naive female control group. Treatment of castrated female rats with testosterone for 7 days resulted in a baseline CPP that was not significantly different from control, but treatment with testosterone for 30 days resulted in a significant $(\mathrm{P}<0.01)$ decrease in baseline CPP. In castrated male rats, treat- ment with estrogen for 30 , but not for 7 , days resulted in a significant $(\mathrm{P}<0.01)$ increase in baseline CPP. Treatment with testosterone for 7 or 30 days did not significantly alter baseline CPP relative to control naive male rats.

Figure 1 shows the results of the regression analysis performed to determine if there was a correlation between right or left ventricular mass and baseline CPP that might explain the higher basal CPP observed in hearts obtained from female rats. No significant correlation was observed between baseline CPP and right ventricular weight. The slopes of the regression line of baseline CPP on left ventricular weight for both male and female rats were significantly different from zero. However, in each case the determination coefficient $\left(\mathrm{r}^{2}\right)$ was small, 0.073 and 0.072 , respectively, for the female and male groups. Thus, the difference in basal CPP (see Table 1, naive groups) in hearts from male and female rats was not explained by differences in ventricular weight. Additionally, it should be noted that there were no effects of castration and/or hormone replacement on ventricular weights.

\section{Serotonin-induced coronary relaxation}

The dose-response curves for coronary vasodilation produced by 5 -HT in isolated hearts obtained from male and female naive

Table 1. Baseline values of coronary perfusion pressure $(\mathrm{mmHg})$ in isolated hearts from the following groups of male and female rats: naive, castrated, and castrated and long-term treated with 17ß-estradiol or testosterone for 7 and 30 days.

\begin{tabular}{|c|c|c|c|c|c|c|}
\hline & \multirow{2}{*}{ Naive } & \multirow{2}{*}{ Castrated } & \multicolumn{2}{|c|}{ 17ß-estradiol } & \multicolumn{2}{|c|}{ Testosterone } \\
\hline & & & 7 days & 30 days & 7 days & 30 days \\
\hline Male & $70 \pm 6(10)$ & $75 \pm 7(8)$ & $84 \pm 4(10)$ & $93 \pm 4(9)^{* *}$ & $76 \pm 3(10)$ & $77 \pm 3(10)$ \\
\hline Female & $115 \pm 6(12)^{\#}$ & $83 \pm 5(8)^{* *}$ & $113 \pm 7(12)$ & $93 \pm 6(10)$ & $96 \pm 3(10)$ & $89 \pm 6(10)^{*}$ \\
\hline
\end{tabular}

Data are reported as means \pm SEM. The number of experiments is given in parentheses. $* \mathrm{P}<0.05$ and $* * \mathrm{P}<0.01$ compared to the respective naive control group (ANOVA followed by Dunnett's test for comparison to control).

\#p $<0.01$ compared to males of the same group (unparied Student t-test). 
and castrated rats and rats castrated and treated with 17ß-estradiol for 7 or 30 days are shown in Figure 2. The dose-response parameters are shown in Table 2. The estimated maximal response for the 5-HT-induced decrease in CPP was greater in hearts obtained from naive female rats (Figure 2, upper panel) than that in hearts from naive male rats (Figure 2, lower panel; $\mathrm{P}<0.05$ ). Although the $\mathrm{E}_{\max }$ for 5-HT-induced coronary relaxation was higher in hearts from naive female rats, there were no significant differences in the potency of 5-HT between hearts obtained from naive male and female rats (Table 2).

In hearts obtained from castrated female rats, although the dose-response curve for 5 HT was slightly shifted to the left, the difference was not significant. The maximum response was significantly $(\mathrm{P}<0.05)$ reduced compared to the curve for the naive female group (Figure 2, top panel). After 7 or 30 days of estrogen treatment of castrated female rats, the $\mathrm{E}_{\max }$ values and $\log \mathrm{ED}_{50}$ values for the actions of 5-HT were not significantly different $(\mathrm{P}>0.05)$ from those for the action of 5-HT on hearts obtained from naive female rats (Figure 2, top panel and Table 2).

In male rats, castration produced a significant decrease in the $\mathrm{E}_{\max }$ for 5-HT when compared to the naive group (Figure 2, bottom panel). Seven days of treatment with estrogen did not alter the effects of castration on the responsiveness to 5-HT. However, after 30 days of estrogen treatment the responsiveness to 5-HT was restored in castrated males (Figure 2, bottom panel). This treatment increased the $\mathrm{E}_{\max }$ to a value similar to that observed in naive female animals. None of the treatments produced significant changes in the potency of 5-HT (Table 2).

The effects of testosterone treatment for 7 or 30 days are shown in Figure 3. In both male and female rats, 30 but not 7 days of treatment with testosterone reversed the castration-induced reduction in responsiveness

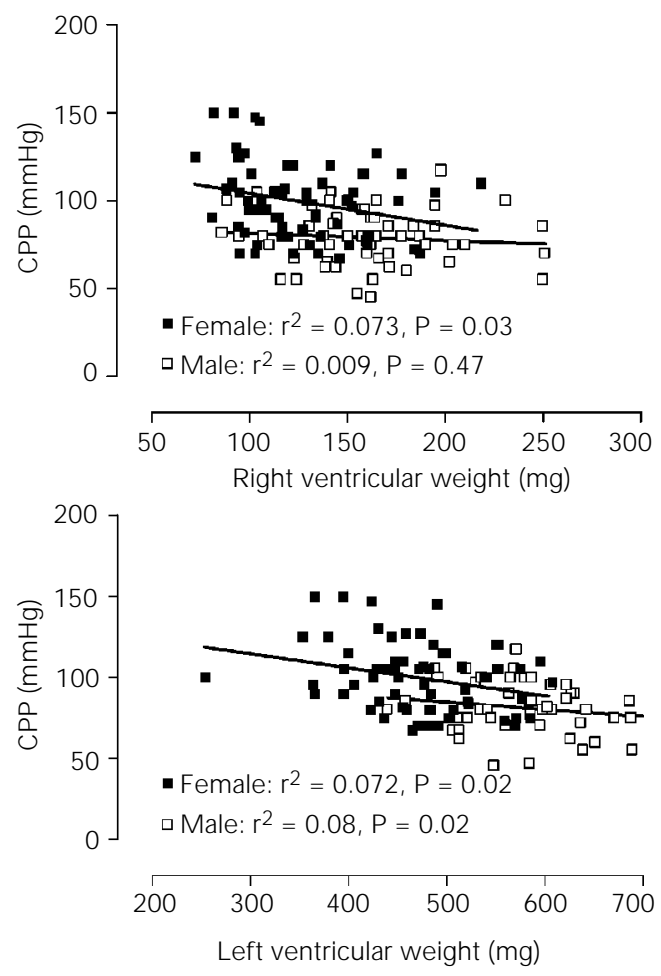

Figure 1. Correlation between baseline coronary perfusion pressure (CPP) and right ventricular weight (top panel) or left ventricular weight (bottom panel) from hearts of male $(\mathrm{N}=58)$ and female $(N=64)$ rats. The thick lines are the regression curves.
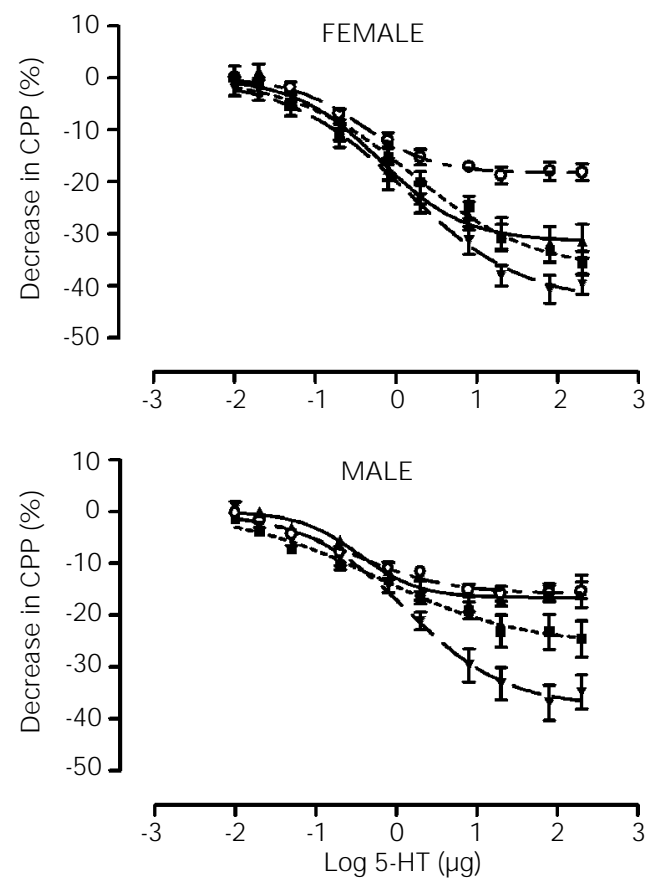

Figure 2. Dose-response curves for coronary vasodilation produced by serotonin (5-HT). Each symbol and bar indicate the mean \pm SEM. The top panel shows the percent decrease in coronary perfusion pressure (CPP) in female rats and the bottom panel shows CPP in male rats.

Female rats

naive $(\mathbf{\square}, \mathbf{N}=12)$

castrated $(\mathrm{O}, \mathrm{N}=8)$

castrated and treated with $17 ß-$ estradiol for 7 days $(\boldsymbol{\Lambda}, \mathbf{N}=12)$ castrated and treated with 17ßestradiol for 30 days $(\boldsymbol{\nabla}, \mathrm{N}=10)$

naive $(\mathbf{\square}, \mathbf{N}=10)$

castrated $(\mathrm{O}, \mathrm{N}=8)$

castrated and treated with 17ßestradiol for 7 days $(\boldsymbol{\Lambda}, N=10)$

castrated and treated with $17 ß-$ estradiol for 30 days $(\boldsymbol{\nabla}, \mathrm{N}=9$ ) 
Table 2. Dose-response parameters for 5-HT-induced coronary vasodilation in hearts obtained from the following groups of male and female rats: naive, castrated, and castrated and treated with either estrogen or testosterone.

\begin{tabular}{|c|c|c|c|c|}
\hline \multirow[t]{2}{*}{ Groups } & \multicolumn{4}{|c|}{ Parameters } \\
\hline & $\log \mathrm{ED}_{50}$ & $E_{\max }$ & $\mathrm{n}$ & $\mathrm{N}$ \\
\hline \multicolumn{5}{|l|}{ Female } \\
\hline Naive & $0.36 \pm 0.21$ & $-40.34 \pm 3.1^{\#}$ & $-0.70 \pm 0.08$ & 12 \\
\hline Castrated & $-0.39 \pm 0.13$ & $-18.71 \pm 0.96 *$ & $-1.05 \pm 0.12$ & 8 \\
\hline \multicolumn{5}{|c|}{ 17ß-estradiol } \\
\hline 7 days & $-0.16 \pm 0.18$ & $-33.40 \pm 4.06$ & $-1.04 \pm 0.12$ & 12 \\
\hline 30 days & $0.34 \pm 0.26$ & $-48.36 \pm 3.58$ & $-0.66 \pm 0.08$ & 10 \\
\hline \multicolumn{5}{|c|}{ Testosterone } \\
\hline 7 days & $-0.29 \pm 0.22$ & $-21.94 \pm 1.05^{*}$ & $-0.92 \pm 0.10$ & 10 \\
\hline 30 days & $-0.06 \pm 0.20$ & $-36.16 \pm 5.27$ & $-0.67 \pm 0.07$ & 10 \\
\hline \multicolumn{5}{|l|}{ Male } \\
\hline Naive & $-0.04 \pm 0.41$ & $-29.10 \pm 3.93$ & $-0.68 \pm 0.11$ & 10 \\
\hline Castrated & $-0.38 \pm 0.28$ & $-18.27 \pm 2.72 *$ & $-0.96 \pm 0.18$ & 8 \\
\hline \multicolumn{5}{|c|}{ 17ß-estradiol } \\
\hline 7 days & $-0.24 \pm 0.15$ & $-18.51 \pm 1.92 *$ & $-1.78 \pm 0.59$ & 10 \\
\hline 30 days & $0.09 \pm 0.13$ & $-38.08 \pm 3.18$ & $-0.76 \pm 0.07$ & 9 \\
\hline \multicolumn{5}{|c|}{ Testosterone } \\
\hline 7 days & $-0.60 \pm 0.17$ & $-16.36 \pm 1.73^{*}$ & $-1.86 \pm 0.75$ & 10 \\
\hline 30 days & $0.06 \pm 0.23$ & $-30.17 \pm 2.96$ & $-0.81 \pm 0.13$ & 10 \\
\hline
\end{tabular}

$E_{\max }$ is the maximum response, log $E_{50}$ is the logarithm of the dose of 5-HT $(\mu \mathrm{g})$ producing one-half maximal response, and $\mathrm{n}$ is a curve-fitting parameter that defines the slope of the dose-response curve. Data are reported as means \pm SEM.

$* \mathrm{P}<0.05$ compared to the respective naive group (ANOVA).

\#P $<0.05$ compared to male naive controls (unpaired Student t-test).

Figure 3. Dose-response curves for coronary vasodilation produced by serotonin $(5-\mathrm{HT})$. Each symbol and bar indicate the mean \pm SEM. The top panel shows the percent decrease in coronary perfusion pressure (CPP) in female rats and the bottom panel shows CPP in male rats.

\section{Female rats}

naive $(\mathbf{\square}, \mathrm{N}=12)$

castrated $(\mathrm{O}, \mathrm{N}=8)$

castrated and treated with testosterone for 7 days $(\mathbf{\Lambda}, \mathrm{N}=10)$ castrated and treated with testosterone for 30 days $(\boldsymbol{\nabla}, \mathrm{N}=10)$

naive $(\mathbf{\square}, \mathbf{N}=10)$

castrated $(\mathrm{O}, \mathrm{N}=8)$

castrated and treated with testosterone for 7 days $(\mathbf{\Lambda}, N=10)$ castrated and treated with testosterone for 30 days $(\nabla, \mathrm{N}=10)$

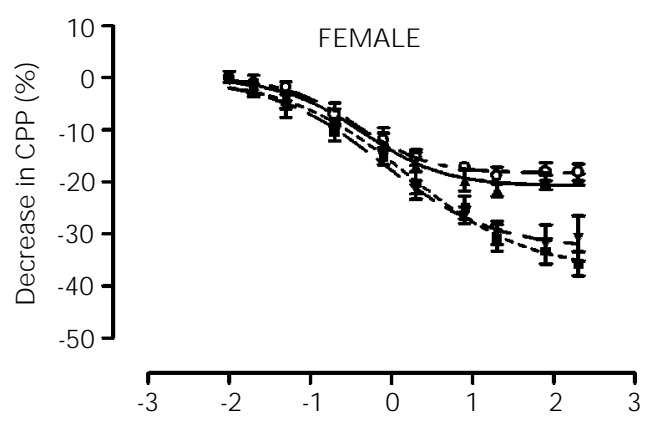

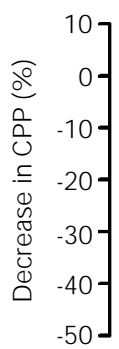
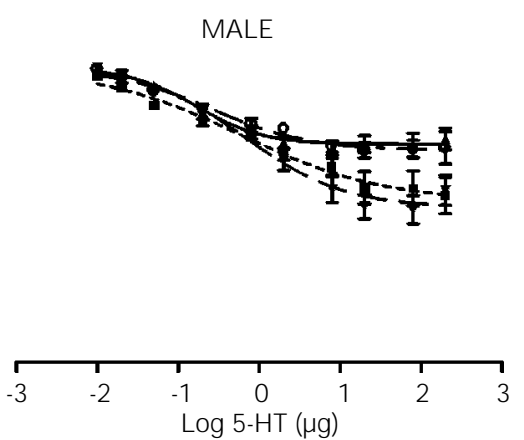

(efficacy or maximal response) to 5-HT. No change was observed in the sensitivity $\left(\mathrm{ED}_{50}\right)$ of the preparation to the different treatments (Table 2).

\section{Endothelium-dependent vasodilation}

The results of studies in which the role of the endothelium in mediating 5-HT coronary vasodilation was examined are shown in Figures 4 and 5 and Table 3. The results presented in Figure 4 show that in the hearts obtained from naive male and female rats, 5 HT-induced vasodilation was abolished after endothelial denudation. These experiments showed a significant difference in $\mathrm{E}_{\max }(\mathrm{P}<0.05)$ between the naive male and female groups before endothelial denudation. The $\log \mathrm{ED}_{50}$ values for 5-HT-induced vasodilation and vasoconstriction were not significantly different between female and male rats (Table 3 ). Figure 5 shows the histological results of the removal of the coronary endothelium of female rats.

\section{Hormone levels}

Castration resulted in significant reductions in the levels of estradiol in female rats (from $44.0 \pm 3.0$ in naive rats to $29.6 \pm 2.0$ $\mathrm{pg} / \mathrm{ml}$ in castrated rats). Similarly, castration resulted in a significant reduction in the levels of testosterone in male rats (from 0.67 $\pm 0.2 \mathrm{ng} / \mathrm{ml}$ in naive rats to undetectable values in castrated rats). In male rats, castration did not alter the plasma levels of estradiol. In castrated female rats, estradiol treatment for 7 or 30 days restored plasma levels to values not significantly different from those seen in naive female rats. In castrated male rats, treatment with testosterone for 7 days partially restored circulating levels of testosterone $(0.37 \pm 0.20 \mathrm{ng} / \mathrm{ml})$ and treatment for 30 days resulted in plasma levels that were not significantly different from those of naive male rats. Interestingly, treatment with testosterone for 30 days of both 
male and female rats was associated with an elevation in plasma 17ß-estradiol levels to $37.0 \pm 3.0 \mathrm{pg} / \mathrm{ml}$ in females and $36.3 \pm 4.0$ $\mathrm{pg} / \mathrm{ml}$ in males, values similar to those seen in naive female rats and castrated female rats treated with 17ß-estradiol.

\section{Discussion}

The present study was carried out on isolated hearts with intact whole coronary vascular beds in the absence of a pharmacological elevation of vascular tone. Under these conditions, we found that basal CPP was significantly higher in hearts obtained from naive female rats than in hearts obtained from male rats. The influence of sex hormones in modulating this difference between groups was demonstrated by castration and subsequent hormone replacement. Castration of female rats reduced CPP to the same values as observed in naive male rats. In contrast, castration of male rats had no effect on basal CPP. Treatment of both castrated male and female rats with $17 \beta$-estradiol for 30 days increased basal CPP. In contrast, treatment of castrated male rats with testosterone had no effects on basal CPP. In castrated female rats, treatment with testosterone for 30 days resulted in an elevation of basal CPP and also restored plasma 17ß-estradiol levels to those seen in naive female rats. Thus, the sex difference in basal CPP seems to be related to the presence of ovarian sex hormones, estrogen in particular.

It may be argued that the augmented value of basal CPP in the female group was due to the smaller size of female hearts. However, the influence of left ventricular weight on basal CPP seems to be minor. The coefficients of determination were similar for both male (0.072) and female (0.073) hearts. Thus, we may conclude that ventricular mass is not responsible for the higher CPP in female rats.

The estrogen-related difference in basal
CPP seems to be paradoxical because estrogen is involved in mechanisms that reduce vascular tone (21). The results of experimental and clinical studies have related estrogen to vascular smooth muscle relaxation both in vitro $(13,18,22,23)$ and in vivo $(17,24-$ 27). However, other actions of estrogen ap-
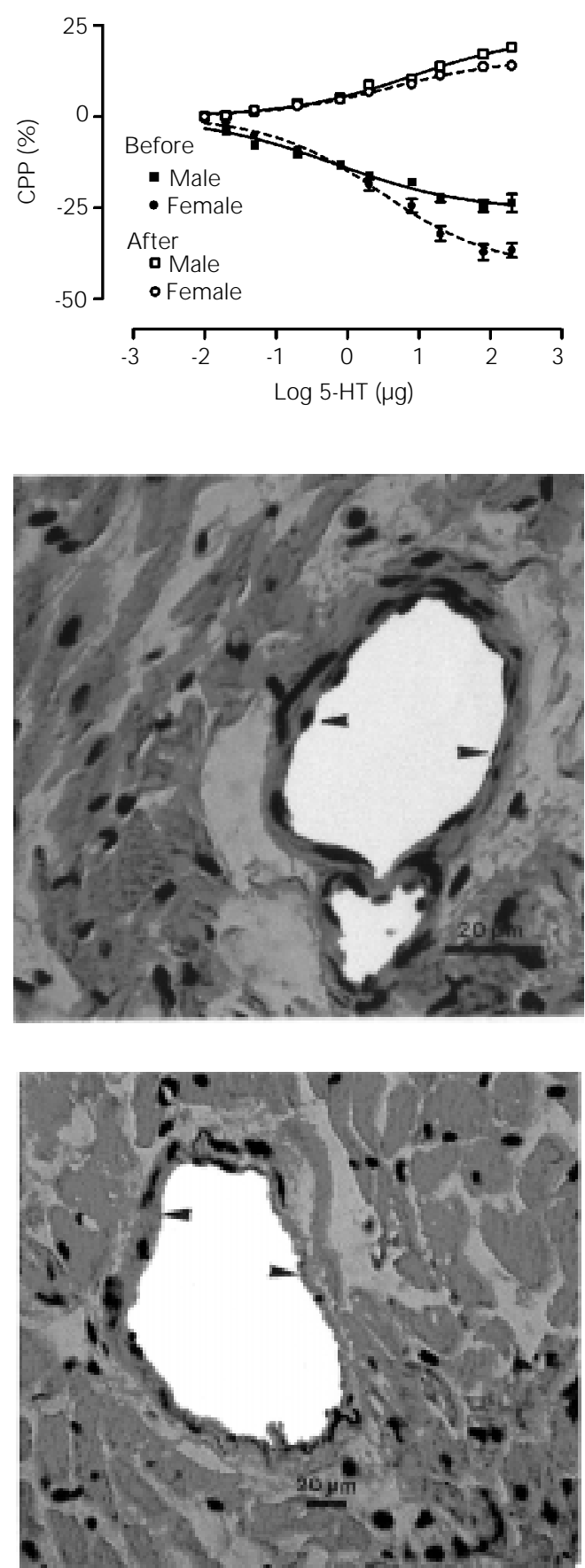

Figure 4. Dose-response curves for coronary vasodilation produced by serotonin (5-HT) in isolated hearts from naive male $(\mathrm{N}$ $=9)$ and female rats $(\mathrm{N}=9)$ before (closed symbols) and after (open symbols, $\mathrm{N}=10$ ) endothelial denudation by treatment with $2 \mathrm{mg} / \mathrm{ml}$ deoxycholic acid in the perfusate for $10 \mathrm{~min}$. Each symbol and bar indicate the mean \pm SEM.

Figure 5. Histological sections perpendicular to the long axis of the heart. The tissues were stained with hematoxylin/eosin and serial blocks were cut at approximately 3-mm intervals. Arrow heads point to a myocardial vessel with the presence of typical endothelial cells (top picture) and a denuded vessel following treatment with deoxycholate (bottom picture). 
pear to exert opposite effects. With respect to the high level of CPP observed in the female group, it is known that estrogen may have indirect effects on the cardiovascular system, e.g., through an interaction with the adrenergic nervous system (28). Many studies have indicated a synergistic effect with sympathetic activity through inhibition of norepinephrine uptake (29), leading to an increase in vascular tonus. An increase in reactivity to norepinephrine has also been shown in oophorectomized (30) and prepuberal rats (23) treated with estrogen. Likewise, the renin-angiotensin system may also be responsible for the high CPP. This system has been associated with intramural reninlike enzyme and angiotensinogen levels in several organs, including the coronary circulation (31). Oelskers (32) demonstrated that $17 ß$-estradiol increased the synthesis of hepatic angiotensinogen, raising the content of angiotensin II and sodium, with a consequent increase in arterial pressure. Further experiments are necessary to elucidate the basis for the estrogen-dependent elevated $\mathrm{CCP}$ and whether this elevation has a role in the cardioprotective effect of estrogen observed in female rats.

5-HT acts on multiple receptors to produce both vasodilator and vasoconstrictor

Table 3. Dose-response parameters for 5 -HT-induced coronary vasodilation in hearts obtained from naive male and female rats before and after endothelial denudation.

\begin{tabular}{lcccr}
\hline Groups & \multicolumn{4}{c}{ Parameters } \\
\cline { 2 - 5 } & Log ED 50 & $E_{\max }$ & $\mathrm{n}$ & $\mathrm{N}$ \\
\hline Female & & & \\
Before & $0.472 \pm 0.14$ & $-44.63 \pm 4.45^{*}$ & $-0.544 \pm 0.05$ & 9 \\
After & $0.597 \pm 0.18$ & $19.83 \pm 0.90$ & $0.79 \pm 0.12$ & 10 \\
& & & & \\
Male & & $-25.83 \pm 22.86$ & $-0.463 \pm 0.08$ & 9 \\
Before & $-0.169 \pm 0.20$ & $25.50 \pm 4.42$ & $0.66 \pm 0.09$ & 10 \\
After & $0.21 \pm 0.32$ & & \\
\hline
\end{tabular}

$E_{\text {max }}$ is the maximum response, log $E_{50}$ is the logarithm of the dose of 5-HT $(\mu \mathrm{g})$ producing one-half maximal response, and $\mathrm{n}$ is a curve-fitting parameter that defines the slope of the dose-response curve. Data are reported as means \pm SEM.

$* \mathrm{P}<0.05$ compared to naive male rats before endothelial denudation (unpaired Student t-test). effects on coronary vascular smooth muscle (33). The relaxant effects mainly depend on the release of nitric oxide from the endothelium and the constrictor effects are due to direct actions on smooth muscle (34). The results of the present study confirm the endothelial dependence of 5-HT-induced coronary vasodilation. Our results are also consistent with the proposed role of estrogen in modulating endothelium-dependent vasodilation (13). The responsiveness to 5-HT, but not the potency of 5-HT, was higher in female than in male hearts. Thus, the influence of estrogen on 5-HT-induced coronary vasodilation seems to involve an increase in the number of functional receptors since only the maximal response was altered. However, this hypothesis needs to be further investigated. Following castration, the maximal response produced by 5-HT was reduced in both male and female rats and the sex difference in responsiveness was no longer seen. Estrogen treatment for either 7 or 30 days restored the responsiveness to 5 HT in the coronary beds of hearts from castrated female rats. On the other hand, castrated male rats were relatively resistant to this action of $17 \beta$-estradiol. In male rats, estrogen treatment for 30 , but not 7 , days restored the responsiveness to $5-\mathrm{HT}$ to a level similar to that seen in hearts from naive female rats. These results demonstrate that 17ß-estradiol modulates the ability of 5-HT to produce an endothelium-dependent vasodilation in the noncontracted coronary bed.

In castrated female and male rats, testosterone treatment for 7 days had no effect on the responsiveness to 5-HT. However, the responsiveness to 5-HT-induced coronary vasodilation in hearts from castrated male and female rats was restored after 30 days of treatment with testosterone. The increase in plasma 17ß-estradiol to levels similar to those seen in naive female rats following 30 days of treatment with testosterone in both male and female castrated rats suggests that the ability of testosterone to restore the respon- 
siveness to 5-HT might have been indirect and due to its conversion to 17ß-estradiol.

Taken together, our observations support the idea that estrogen modulates endothelium-dependent vasodilation. The ability of estrogen replacement to restore the endothelium-dependent vasodilator response in the intact coronary bed in castrated female rats is consistent with other studies that have shown this effect of estrogen replacement $(13,15)$. Estrogen receptors are present in vascular endothelial cells and vascular smooth muscle cells $(35,36)$ where they play a modulator role in the basal release of nitric oxide (NO) $(37,38)$. Furthermore, 17ß-estradiol has been recently reported to enhance expression of constitutive NO-synthase in cultured vascular endothelial cells and to induce both the neuronal and endothelial isoenzymes of NO-synthase in estrogentreated animals $(39,40)$. Corroborating these experimental studies, Rosselli et al. (26) showed that serum nitrite and nitrate levels are higher in postmenopausal women submitted to hormone replacement therapy, providing indirect evidence of enhanced NO production induced by estrogen. Thus, estrogen-induced enhancement of NO release may be an important underlying mechanism in the cardioprotective effect of estrogen.

Our results indicate that differences in coronary vascular reactivity to 5 -HT in isolated hearts from male and female rats are probably modulated by 173 -estradiol and may be associated with higher release of endothelium vasodilator autacoids. Knowledge of the mechanism of action of estrogen on coronary arteries could aid in the development of new therapeutic strategies in which the cardioprotective effects might be separated from other components of estrogen activity, potentially decreasing the incidence of cardiovascular disease in both sexes.

\section{References}

1. Luscher TF \& Vanhoutte PM (1990). The Endothelium: Modulator of Cardiovascular Function. CRC Press, Boca Raton.

2. Crofton J T, Ratliff DL, Brooks DP \& Share $L$ (1986). The metabolic clearance rate of and pressor responses to vasopressin in male and female rats. Endocrinology, 118: 1777-1781.

3. Freedman RR, Sabharwal SC \& Desai N (1987). Sex differences in peripheral vascular adrenergic receptors. Circulation Research, 61: 581-585.

4. Zhang F, Ram J L, Standley PR \& Sowers J R (1994). 17ß-Estradiol attenuates voltage-dependent $\mathrm{Ca}^{2+}$ currents in A7r5 vascular smooth muscle cell line. American J ournal of Physiology, 266: C975-C980.

5. Kannel WB, Hjortland MC, M CNamara PM \& Gordon T (1976). Menopause and risk of cardiovascular disease: The Framingham Study. Annals of Internal Medicine, 85: 447-452.

6. Rowland NE \& Fregly MJ (1992). Role of gonadal hormones in hypertension in the Dahl salt-sensitive rat. Clinical and Experimental Hypertension, 14: 367-375.

7. Stampfer MJ, Colditz GA, Willett WC, Manson JAE, Rosner B, Speizer FE \&
Hennekens CH (1991). Postmenopausal estrogen therapy and cardiovascular disease: Ten year follow-up from the Nurses' Health Study. New England J ournal of Medicine, 325: 756-762.

8. Grady D, Rubin SM \& Petiti DB (1992). Hormone therapy to prevent disease and prolong life in postmenopausal women. Annals of Internal Medicine, 117: 10161037.

9. Walsh BW, Schiff I, Rosner B, Greenberg L, Ravnikar V \& Sacks FM (1991). Effects of postmenopausal oestrogen replacement on the concentrations and metabolism of plasma lipoproteins. New England J ournal of Medicine, 325: 1196-1204.

10. Bush TL, Barret-Connor E, Cowan LD, Criqui $M H$, Wallace RB, Suchindran CM, Tyroler HA \& Rifkind BM (1987). Cardiovascular mortality and noncontraceptive use of estrogen in women: Results from the Lipid Research Clinics Program Follow Up Study. Circulation, 75: 1102-1109.

11. Barret-Connor E \& Bush TL (1991). Estrogen and coronary heart disease in women. J ournal of the American Medical Association, 265: 1861-1867.

12. Adams MR, Clarkson TB, Kaplan JR \&
Koritnik DR (1990). Ovarian secretions and atherosclerosis. In: Naftolin F, Gutmann J N, DeCherney AH \& Sarrel PM (Editors), Ovarian Secretions and Cardiovascular and Neurological Function. Raven Press, New York, 151-159.

13. Gisclard V, Miller VM \& Vanhoutte PM (1988). Effect of 17ß-estradiol on endothelium-dependent responses in the rabbit. J ournal of Pharmacology and Experimental Therapeutics, 244: 19-22.

14. Hayashi T, Fukuto J M, Ignarro LJ \& Chaudhuri $G$ (1992). Basal release of nitric oxide from aortic rings is greater in female rabbits than in male rabbits: implications for atherosclerosis. Proceedings of the National Academy of Sciences, USA, 89: 11259-11263.

15. Van-Buren GA, Yang D \& Clark KE (1992). Estrogen-induced uterine vasodilatation is antagonized by L-nitroarginine methyl ester, an inhibitor of nitric oxide synthesis. American J ournal of Obstetrics and Gynecology, 167: 828-833.

16. Collins $P$, Rosano GMC, J iang $C$, Lindsay D, Sarrel PM \& Poole-Wilson PA (1993). Cardiovascular protection by oestrogen a calcium antagonist effect? Lancet, 341: 
1264-1265.

17. Magness R \& Rosenfeld CR (1989). Local and systemic estradiol-17ß: effects on uterine and systemic vasodilation. American J ournal of Physiology, 256: E536E542.

18. J iang C, Sarrel PM, Lindsay DC, PooleWilson PA \& Collins P (1991). Endothelium-independent relaxation of rabbit coronary artery by $17 ß-o e s t r a d i o l$ in vitro. British J ournal of Pharmacology, 104: 10331037.

19. De Clerck F \& Reneman RS (1985). Platelet-derived serotonin and abnormal tissue perfusion. In: De Clerck F \& Vanhoutte PM (Editors), Serotonin and the Cardiovascular System. Raven Press, New York, 155-163.

20. Golino $P$, Piscione $F$, Willerson $J T$, Cappelli-Bigazzi M, Focaccio A, Villari B, Irdolfi C, Russolillo $\mathrm{E}$, Condorelli $\mathrm{M}$ \& Chiariello M (1991). Divergent effects of serotonin on coronary artery dimensions and blood flow in patients with coronary atherosclerosis and control patients. New England J ournal of Medicine, 324: 641648.

21. Riedel $M$, Oeltermann $A, M u ̈ g g e ~ A$, Creutzig A, Rafflenbeul W \& Lichtlen P (1995). Vascular responses to $17 ß$-oestradiol in postmenopausal women. European J ournal of Clinical Investigation, 25: 4447.

22. Farhat MY, Abi-Younes $S \&$ Ramwell PM (1996). Nongenomic effects of estrogen and the vessel wall. Biochemical Pharmacology, 51: 571-576.

23. Cheng DY \& Gruetter CA (1992). Chronic estrogen alters contractile responsiveness to angiotensin II and norepinephrine in female rat aorta. European J ournal of Pharmacology, 215: 171-176.
24. Gilligan DM, Badar DM, Panza J Á, Quyyumi AA \& Cannon RO (1994). Acute vascular effects of estrogen in postmenopausal women. Circulation, 90: 786-791.

25. Taddei S, Virdis A, Ghiadoni L, Mattei $P$, Sudano I, Bernini G, Pinto $S \&$ Salvetti A (1996). Menopause is associated with endothelial dysfunction in women. Hypertension, 28: 576-582.

26. Rosselli M, Imthurn B, Keller PJ , J ackson EK \& Dubey RK (1995). Circulating nitric oxide (nitrite/nitrate) levels in postmenopausal women substituted with 17ß-estradiol and norethisterone acetate. Hypertension, 25: 848-853.

27. Rosano GMC, Sarrel PM, Poole-Wilson PA \& Collins P (1993). Beneficial effect of oestrogen on exercise-induced myocardial ischaemia in women with coronary artery disease. Lancet, 342: 133-136.

28. Colucci WS, Gimbrone MA, McLaughlin MK, Halpern W \& Alexander RW (1982). Increased vascular catecholamine sensitivity and alpha 1-adrenergic receptor affinity in female and estrogen treated male rats. Circulation Research, 50: 805-811.

29. Hamlet MA, Rorie DK \& Tyce GM (1980). Effects of estradiol on release and disposition on norepinephrine from nerve endings. American J ournal of Physiology, 239: $\mathrm{H} 450-\mathrm{H} 456$.

30. Rorie DK \& Muldoon SM (1979). Increased reactivity of isolated rabbit saphenous vein after treatment with estrogen and progesterone. Blood Vessels, 16: 252-258.

31. Dzau VJ (1988). Circulating versus local renin-angiotensin system in cardiovascular homeostasis. Circulation, 77 (Suppl I): 4-13.

32. Oelskers WKH (1996). Effects of estrogens and progestogens on the renin-aldo- sterone system and blood pressure. Steroids, 61: 166-171.

33. Houston DS \& Vanhoutte PM (1988). Comparison of serotonergic receptor subtypes on the smooth muscle and endothelium of the canine coronary artery. J ournal of Pharmacology and Experimental Therapeutics, 244: 1-10.

34. Kelm M \& Schrader J (1990). Control of coronary vascular tone by nitric oxide. Circulation Research, 66: 1561-1575.

35. Colburn P \& Buonassisi V (1978). Estrogen binding sites in endothelial cell cultures. Science, 201: 817-819.

36. Horwitz KB \& Horwitz CD (1982). Canine vascular tissue are targets for androgens, estrogens, progestins and glucocorticoids. J ournal of Clinical Investigation, 69: 750-758.

37. Losordo DW, Kearney M, Kim EA, J ekanowski J \& Isner J M (1994). Variable expression of the estrogen receptor in normal and atherosclerotic coronary arteries in premenopausal women. Circulation, 89: 1501-1510.

38. Hayashi T, Yamada K, Esaki T, Kuzuya M, Satake S, Ishikawa T, Hidaka H \& Iguchi A (1995). Estrogen increases endothelial nitric oxide by a receptor mediated system. Biochemical and Biophysical Research Communications, 214: 847-855.

39. Schray-Utz B, Zeither AM \& Busse R (1993). Expression of constitutive NO synthase in cultured endothelial cells is enhanced by 17 ß-estradiol. Circulation, 88 (Suppl I): I-80 (Abstract).

40. Weiner CP, Lizasoain I, Baylis AS, Knowles RG, Charles IG \& Moncada S (1994). Induction of calcium-dependent nitric oxide synthases by sex hormones. Proceedings of the National Academy of Sciences, USA, 91: 5212-5216. 